\title{
EFEKTIFITAS PENGGUNAAN CaO SEBAGAI KATALIS HETEROGEN DIBANDINGKAN KATALIS HOMOGEN UNTUK PRODUKSI BIODIESEL
}

\author{
Yuhelson $^{1}$, Prasetya ${ }^{2}$, M. Ridha Fauzi ${ }^{1}$, Puri Triasih ${ }^{2}$
}

\author{
1. Program Teknik Otomotif, Fakultas Teknik, Universitas Muhammadiyah Riau \\ 2. Program Studi Kimia, Fakultas MIPA dan Kesehatan, Universitas Muhammadiyah Riau \\ Jl. KH. Ahmad Dahlan No. 88. Sukajadi. Pekanbaru \\ e-mail korespondensi: prasetya.go@gmail.com
}

\begin{abstract}
ABSTRAK
Biodiesel diharapkan dapat menggantikan solar sebagai sumber energi alternatif terbarukan yang memiliki keunggulan lain seperti bahan baku terbarukan, lebih ramah lingkungan dan dapat langsung digunakan pada kendaraan. Namun, biaya produksi biodiesel masih cukup tinggi sehingga belum dapat bersaing dengan solar. Pada penelitian ini dilakukan efisiensi pada katalis. Biodiesel yang dihasilkan menggunakan katalis homogen yang umum digunakan $(\mathrm{NaOH})$ dibandingkan dengan katalis heterogen $(\mathrm{CaO})$. Hasil yang diperoleh menunjukkan rendemen katalis $\mathrm{NaOH}$ lebih tinggi yaitu $83,75 \%$.
\end{abstract}

Kata kunci: biodiesel, katalis, energi, karakterisasi,

\section{PENDAHULUAN}

Biodiesel diharapkan dapat menggantikan solar sebagai sumber energi alternatif terbarukan yang memiliki keunggulan lain seperti lebih ramah lingkungan dan dapat langsung digunakan pada kendaraan serta mesin yang ada sekarang tanpa perlu modifikasi lebih lanjut.

Untuk mempercepat pembentukan biodiesel mutlak diperlukan suatu katalis. Jadi, katalis memegang peranan yang amat penting pada produksi biodiesel (Awaluddin, 2005). Reaksi transesterifikasi dengan katalis basa biasanya menggunakan logam alkali alkoksida, $\mathrm{NaOH}$, $\mathrm{KOH}$, dan $\mathrm{NaHCO}_{3}$. Penggunaan katalis ini memiliki kelemahan, yaitu pemisahan katalis dari produknya relatif sulit sehingga akan meningkatkan biaya produksi (Serio dkk, 2005). Sisa katalis basa juga dapat mengganggu pengolahan lanjut biodiesel yang dihasilkan (Herman dan Zahrina, 2006). Untuk itu perlu dibuat katalis heterogen yang lebih mudah untuk dipisahkan dan memiliki efektivitas katalitik yang tinggi.

Cruz (2007) mencoba berbagai jenis katalis seperti $\mathrm{BaO}, \mathrm{MgO}$ dan $\mathrm{K}_{2} \mathrm{CO}_{3}$ untuk untuk mengamati produksi biodiesel dan hasilnya menunjukkan bahwa produksi biodiesel maksimum yang diperoleh adalah sebanyak
$85 \%$. Produksi biodiesel yang diperoleh ternyata erat kaitannya dengan kekuatan basa dari katalis.

Untuk mencari katalis heterogen yang memiliki efisiensi yang baik, murah dan mudah didapat, maka perlu dilakukan upaya inventarisasi terhadap kemampuan katalis heterogen dalam memproduksi biodiesel. Salah satu katalis heterogen yang sangat potensial untuk peningkatan jumlah produksi dan menurunkan biaya produksi biodiesel adalah $\mathrm{CaO}$. Kajian penggunaan $\mathrm{CaO}$ akan dibandingkan dengan $\mathrm{NaOH}$ sebagai katalis homogen pada produksi biodiesel.

\section{METODOLOGI PENELITIAN Preparasi Minyak Jelantah}

Minyak goreng bekas yang digunakan berasal dari minyak bekas penggorengan fried chicken pedagang kaki lima di kecamatan Sukajadi, Pekanbaru. Minyak goreng bekas yang telah dikumpulkan disaring terlebih dahulu dengan kertas saring untuk menghilang endapan maupun zat sisa penggorengan lainnya.

Penentuan asam lemak bebas (Nurhayati dan Huda, 2014)

Sebanyak 20 gram minyak jelantah ditimbang dan dimasukkan kedalam erlenmeyer $250 \mathrm{ml}$. Selanjutnya ditambahkan $50 \mathrm{ml}$ Iso 
Propil Alkohol, 2-3 tetes indikator PP dan kemudian diaduk sampai homogen. Larutan ini kemudian dititrasi dengan larutan $\mathrm{KOH} 0,1 \mathrm{~N}$ (standar sekunder) sampai timbul warna merah muda (pink).

Larutan standar sekunder $(\mathrm{KOH})$ dititrasi dengan standar primer Potasium Hidro Phtalat (PHP). Asam lemak bebas ditentukan dengan persamaan berikut :

Normalitas $\mathrm{KOH}=\frac{\text { berat PHP (gram) } \times 1000}{\text { V KOH x 204,2 }}$

Asam Lemak bebas $(\%)=(\mathrm{ml} \times \mathrm{N}) \mathrm{KOH} \times 256 \times 100 \%$

Catatan : BM PHP $=204,2$ Gram sampel $x 1000$

\section{Preparasi Katalis $\mathrm{CaO}$}

$\mathrm{CaO}$ diayak dengan menggunakan ayakan 100 mesh. Kemudian $\mathrm{CaO}$ dikalsinasi dalam furnace pada suhu $950^{\circ} \mathrm{C}$ selama 3 jam untuk menghilangkan pengotor. Setelah proses kalsinasi selesai, katalis $\mathrm{CaO}$ yang dihasilkan disimpan di dalam desikator untuk menjaga kondisi katalis tetap kering.

\section{Sintesis Biodiesel}

Sintesis biodiesel dilakukan dengan menggunakan proses metanolisis antara minyak jelantah dan metanol. Minyak jelantah ditransesterifikasi dengan metanol menggunakan katalis $\mathrm{CaO}$ yang telah dipreparasi sebelumnya. Proses transesterifikasi dilakukan dengan menghomogenkan katalis $\mathrm{CaO}$ sebanyak 8, 25 gram dan metanol sebanyak $165 \mathrm{ml}$ selama \pm 30 menit. Setelah homogen, $825 \mathrm{ml}$ minyak jelantah ditambahkan kedalam campuran tersebut sambil diaduk dan dipanaskan pada suhu $65^{\circ} \mathrm{C}$ selama 2 jam. Biodiesel yang diperoleh kemudian disaring dengan menggunakan kertas saring untuk memisahkan campuran biodiesel dengan katalis $\mathrm{CaO}$. Setelah terpisah, biodiesel dimasukkan kedalam corong pisah dan didiamkan selama 1 malam untuk memisahkan biodiesel dengan gliserol. Biodiesel yang terbentuk pada lapisan atas diambil kemudian dicuci dengan air hangat (suhu \pm $50^{\circ} \mathrm{C}$ ). Kemudian biodiesel dimurnikan dengan pemanasan pada suhu $100^{\circ} \mathrm{C}$.

\section{Karakterisasi Biodiesel}

Penentuan berat jenis (Ketaren, 2005)

Piknometer yang bersih dan kering ditentukan massanya, lalu diisi dengan biodiesel.
Kemudian ditutup hingga ada biodiesel yang keluar dari lubang tutup piknometer. Piknometer beserta isinya ditimbang. Selanjutnya piknometer dibersihkan dan dikeringkan. Massa jenis biodiesel ditentukan dengan persamaan:

Massa jenis $=\underline{\text { (massa piknometer berisi biodiesel })-(\text { massa piknometer kosong })}$ Volume piknometer

\section{Penentuan bilangan asam (Nurhayati dan} Huda, 2014)

Ditimbang 19-21 \pm 0,05 gram biodiesel dan dimasukkan ke dalam erlenmeyer $250 \mathrm{ml}$. Ditambahkan $100 \mathrm{ml}$ alkohol netral 95\%. Selanjutnya dipanaskan selama 10 menit dalam penangas air sambil diaduk. Dalam keadaan teraduk kuat, larutan dititrasi dengan larutan $\mathrm{KOH} \quad 0,1 \mathrm{~N}$ (distandarisasi dengan standar primer PHP) dengan indikator PP sampai terbentuk warna merah jambu (pink). Catat volume $\mathrm{KOH}$ yang terpakai. Bilangan asam dapat ditentukan dengan persamaan berikut :

Normalitas $\mathrm{KOH}=$ Berat PHP $($ gram $) \times 1000$

$\mathrm{V} \mathrm{KOH} \times 204,2$

Asam lemak bebas (\%) $=(\mathrm{V} \times \mathrm{N}) \mathrm{KOH} \times 256 \times 100 \%$ Gram sampel x 1000

Penentuan kandungan air (Nurhayati dan Huda, 2014)

Cawan porselen bersih dikeringkan dalam oven dengan suhu $105^{\circ} \mathrm{C}$ selama 60 menit. Selanjutnya didinginkan dalam desikator dan ditimbang. Lebih kurang 10 gram biodiesel ditimbang didalam cawan porselen diatas kemudian cawan porselen ini dimasukkan dalam oven dan dipanaskan pada suhu $105^{\circ} \mathrm{C}$ selama 3 jam. Setelah 3 jam cawan porselen didinginkan dalam desikator dan ditimbang kembali. Pekerjaan ini dilakukan berulang kali sampai berat yang diperoleh konstan.

Penentuan angka iodium (Nurhayati dan Huda, 2014)

\section{- Untuk sampel}

Sebanyak 0,05 gr biodiesel ditambahkan ke dalam erlenmeyer yang berisi $2 \mathrm{ml}$ kloroform dan $5 \mathrm{ml}$ reagen Hanus dan dibiarkan ditempat gelap selama 30 menit. Selanjutnya ditambahkan $10 \mathrm{ml}$ larutan KI $15 \%$ dan $50 \mathrm{ml}$ aquades yang telah didinginkan, dan segera dititrasi dengan larutan natrium tiosulfat $0,1 \mathrm{~N}$ sampai larutan berwarna kuning pucat, kemudian ditambahkan 
3 tetes larutan pati. Titrasi dilanjutkan sampai warna hilang.

\section{- Untuk blanko}

Sebanyak $5 \mathrm{ml}$ reagen Hanus dalam erlenmeyer ditambahkan $2 \mathrm{ml}$ KI $15 \%$, kemudian diencerkan dengan aquades $20 \mathrm{ml}$ yang telah dididihkan dan dititrasi dengan larutan natrium tiosulfat untuk menghitung bilangan iodin digunakan rumus :

Bilangan iodin $=\underline{\text { ml titrasi }(\text { blanko-sampel }) \times \mathrm{N} \text { thio } \times 12,691}$

$$
\text { Berat sampel (gr) }
$$

\section{HASIL DAN PEMBAHASAN}

Tabel 1. Hasil sintesis biodiesel

\begin{tabular}{|c|c|l|c|}
\hline NO & $\begin{array}{c}\text { Perbandingan } \\
\text { Minyak : Metanol } \\
\mathbf{:} \text { Katalis }\end{array}$ & Warna & $\begin{array}{c}\text { Rendemen } \\
(\mathbf{\%} \mathbf{v} \\
\text { minyak })\end{array}$ \\
\hline 1 & $5: 1: 1 \% \mathrm{CaO}$ & $\begin{array}{l}\text { Kuning } \\
\text { Jernih }\end{array}$ & 32,73 \\
\hline 2 & $5: 1: 1 \% \mathrm{NaOH}$ & $\begin{array}{l}\text { Kuning } \\
\text { Jernih }\end{array}$ & 83,75 \\
\hline
\end{tabular}

Table 2. Karakterisasi Biodiesel

\begin{tabular}{|c|l|c|c|c|c|}
\hline NO & Parameter & Satuan & CaO & NaOH & SNI \\
\hline 1 & $\begin{array}{l}\text { Densitas } \\
\text { Biodiesel }\end{array}$ & $\left(\mathrm{kg} / \mathrm{m}^{3}\right)$ & 860 & 857 & $850-890$ \\
\hline 2 & Jumlah Air & $\%$ & $<0.05$ & $<0.05$ & $\begin{array}{c}\text { Maks. } \\
0,05\end{array}$ \\
\hline 3 & Sedimen & $\%$ & 3,83 & - & $\begin{array}{c}\text { Maks. } \\
0,05\end{array}$ \\
\hline 4 & $\begin{array}{l}\text { Angka } \\
\text { Iodium }\end{array}$ & $\begin{array}{c}\text { massa } \\
(\mathrm{g}-12 / 100 \mathrm{~g})\end{array}$ & 60,34 & 62,82 & $\begin{array}{c}\text { Maks. } \\
115\end{array}$ \\
\hline 5 & $\begin{array}{l}\text { Angka } \\
\text { asam }\end{array}$ & $\mathrm{mg}-\mathrm{KOH} / \mathrm{g}$ & 0,6 & 0,82 & Maks 0,8 \\
\hline
\end{tabular}

Proses sintesis biodiesel dengan minyak jelantah dan metanol dilakukan dengan menggunakan perbandingan antara minyak: metanol: katalis sebesar 5:1:1\% katalis (dari berat minyak) dan pemanasan pada suhu $65^{\circ} \mathrm{C}$ selama 120 menit. Dimana, menurut Hikmah dan Zuliyana (2010), waktu optimum untuk proses transesterifikasi biodiesel adalah selama 120 menit.

Pada perbandingan dan waktu tersebut rendemen biodiesel yang dihasilkan yaitu 32,73 $\%$ dengan $\mathrm{CaO}$ dan $83,75 \%$ dengan $\mathrm{NaOH}$. Rendahnya rendemen biodiesel yang dihasilkan tersebut diasumsikan karena kecilnya jumlah katalis yang digunakan. Sebab menurut Wei dkk (2009), ketika digunakan katalis yang $<1 \%$ (berat minyak) produk yang dihasilkan tidak maksimal, sedangkan bila katalis $>10 \%$, maka campuran katalis dan reaktan akan menjadi terlalu kental, sehingga hasil yang terbentuk juga tidak optimal. Ia juga menjelaskan bahwa yield tidak akan meningkat bila katalis yang digunakan lebih dari $3 \%$. Selain itu, dari berbagai literatur menjelaskan bahwa perbandingan terbesar adalah pada metanol. Dimana semakin banyak metanol yang digunakan maka semakin banyak pula metil ester (biodiesel) yang dihasilkan (Faizal dkk, 2013).

\section{Massa jenis}

Kedua biodiesel yang dihasilkan memenuhi SNI biodiesel untuk parameter massa jenis (densitas) yaitu $850-890 \mathrm{~kg} / \mathrm{m}^{3}$. Massa jenis biodiesel yang dihasilkan adalah $860(\mathrm{CaO})$ dan $857 \mathrm{~kg} / \mathrm{m}^{3}(\mathrm{NaOH})$. Biodiesel yang mempunyai massa jenis melebihi ketentuan, akan terjadi reaksi tidak sempurna pada konversi minyak jelantah. Biodiesel dengan mutu seperti ini tidak bisa digunakan untuk mesin diesel karena akan meningkatkan keausan mesin, emisi, dan menyebabkan kerusakan pada mesin (Syamsidar, 2013).

\section{Angka asam}

Angka asam biodiesel dengan katalis $\mathrm{CaO}$ memenuhi SNI 04-7182-2012 (maks 0,8 mg$\mathrm{KOH} / \mathrm{g}$ ) yaitu $0,6 \mathrm{mg}-\mathrm{KOH} / \mathrm{g}$. Sedangkan biodiesel dengan katalis $\mathrm{NaOH}$ lebih tinggi yaitu $0,82 \mathrm{mg}-\mathrm{KOH} / \mathrm{g}$. Angka asam yang tinggi merupakan indikator biodiesel yang masih mengandung asam lemak bebas (Syamsidar, 2013).

\section{Kandungan air dan sedimen}

Berdasarkan hasil pengujian kandungan air dan sedimen, pada sampel biodiesel dari katalis $\mathrm{NaOH}, \quad \mathrm{CaO}$ tidak menunjukkan adanya kandungan air dan sedimen. Hal ini menunjukkan bahwa pada saat proses pemisahan katalis heterogen yang digunakan terpisah sepenuhnya, dan pada saat proses pemurnian air yang tersisa dari proses pencucian sebelumnya juga telah menguap sepenuhnya. Namun pada katalis $\mathrm{CaO}$, biodiesel yang dihasilkan masih terdapat kandungan sedimen masing-masingnya $3,83 \%$. Terdapatnya kandungan sedimen dalam 
sampel biodiesel tersebut dikarenakan pada saat proses pemisahan, katalis $\mathrm{CaO}$ tidak terpisah sepenuhnya, sehingga pada saat proses pemurnian katalis tersebut masih tersisa di dalam biodiesel. Nilai kandungan sedimen tersebut masih terlalu tinggi dan belum memenuhi syarat mutu SNI 04-7182-2012. Sehingga biodiesel yang dihasilkan belum bisa diaplikasikan pada mesin diesel sebab menurut Nurhayati (2014), sedimen yang terdapat dalam biodiesel dapat menyumbat dan merusak mesin. Sehingga perlu dilakukan proses pemisahan dan pengujian lebih lanjut untuk mendapatkan biodiesel yang sesuai standar.

\section{Angka Iodium}

Angka iodium merupakan parameter yang digunakan untuk menunjukkan banyaknya ikatan rangkap dua dalam asam lemak penyusun biodiesel. Biodiesel dengan kandungan angka iodium yang tinggi (>115) akan mengakibatkan kecenderungan untuk terpolimerisasi dan membentuk deposit pada mesin saat proses pembakaran (Setiawati dan Edwar, 2012).

Pada uji angka iodium, biodiesel yang disintesis dengan menggunakan katalis $\mathrm{CaO}$ dan $\mathrm{NaOH}$ masing-masing adalah 60,34 dan $62,82 \mathrm{~g}$ $12 / 100$ g. Angka iodium tersebut memenuhi syarat mutu SNI 04-7182-2012. Sehingga, biodiesel tersebut diharapkan dapat digunakan sebagai bahan bakar pengganti solar.

\section{KESIMPULAN}

Secara kuantitatif, rendemen biodiesel yang menggunakan katalis homogen $(\mathrm{NaOH})$ lebih tinggi yaitu 83,75 \% dibandingkan katalis heterogen $(\mathrm{CaO})$ yaitu $32,73 \%$. Namun, secara kualitatif, biodiesel yag dihasilkan dari kedua katalis memenuhi persyaratan SNI 04-71822012, dan $\mathrm{CaO}$ memiliki keunggulan pada kandungan asam yang lebih baik. Berdasarkan hasil tersebut, maka dapat diketahui bahwa katalis heterogen $(\mathrm{CaO})$ memiliki potensi menghasilkan biodiesel yang ekonomis dan ramah lingkungan. Meskipun demikian, masih perlu dilakukan optimalisasi seperti faktor kinetika reaksi jika ingin dikembangkan pada skala komersil.

\section{DAFTAR PUSTAKA}

Awaluddin, A., Saryono, Wikara, T., Amri, T. A. 2005. The Use of $\mathrm{NaOH}$ as Homogeneous Catalyst for Biodiesel Production, Proceeding Seminar UNRIUKM ke-4..

Cruz, A., Mangesh K. G, 2007. Synthesis of Biodiesel from Canola Oil Using Heterogeneous Base Catalys, J Am Oil Chem Soc. 84 : 937-943

Faizal, M., Maftuchah, U., dan Auriyani, W.A., 2013. Pengaruh Kadar Metanol, Jumlah Katalis, Dan Waktu Reaksi Pada Pembuatan Biodiesel Dari Lemak Sapi Melalui Proses Transesterifikasi. Jurnal Teknik Kimia. No. 4, Vol. 19.

Herman, S., dan Zahrina. 2006. Kinetika Reaksi Metanolisis Minyak Sawit Menggunakan Katalis Heterogen. Jurnal Sains dan Teknologi. Volume 5. No.2 ISSN: 1412-6257. Fakultas Teknik Universitas Riau, Pekanbaru

Hikmah, M.N., dan Zuliyana., 2010. Pembuatan Metil Ester (Biodiesel) Dari Minyak Dedak Dan Metanol Dengan Proses Esterifikasi Dan Transesterifikasi. Skripsi. Jurusan Teknik Kimia. Universitas Diponegoro.

Ketaren, S., 2005, Pengantar Teknologi Minyak dan Lemak Pangan. UI Press, Jakarta.

Nurhayati dan Huda, N., 2014. Proses Pengolahan Bahan Baku Biomassa Menjadi Biodiesel. Kementerian Pendidikan dan Kebudayaan: Bandung.

Setiawati, E., dan Edwar, F., 2012. Teknologi Pengolahan Biodiesel Dari Minyak Goreng Bekas Dengan Teknik Mikrofiltrasi Dan Transesterifikasi Sebagai Alternatif Bahan Bakar Mesin Diesel. Jurnal Riset Industri. Vol. VI. No. 2. Hal. 117-127.

Syamsidar, HS. 2013. Pembuatan dan Uji Kualitas Biodiesel dari Minyak Jelantah. Jurnal Teknosains, Volume 7. Nomor 2. hlm: 209-218.

Wei, Z., Chunli, X., dan Li, B., 2009. Application of waste eggshell as lowcost solid catalyst for biodiesel production. Bioresource Technology. 100 (2009) 2883-2885. 